\title{
O TEMA DE THE HOLLOW MEN EM HEART OF DARKNESS DE JOSEPH CONRAD *
}

\author{
Sigrid Renaux th
}

Durante a leitura de Heart of Darkness 1 (1902) impressionou-nos a grande recorrência de imagens também achadas nos poemas de T.S. Eliot, principalmente em The Wasteland (1922) e The Hollow Men 2 (1925). Entretanto, concentrar-nos-emos especificamente na imagem dos "hollow men" 3, poema que tem como epigrama uma citaçāo de Heart of Darkness: "Mistah Kurtz - he dead"

Se, por um lado, Marlow e Kurtz são as personagens principais do romance, o primeiro aproximando-se gradualmente do segundo para descobrir que a busca em que ele estava engajado na realidade apenas lhe revelaria o horror encontrado no âmago de Kurtz, por outro lado as personagens secundárias servem de certo modo de contraste, de pano de fundo ao caminho sinuoso que leva Marlow ao coraçāo da Africa.

O tema dos "hollow men", assimilado por Eliot e transposto em seu poema de 1925, realmente atravessa todo o romance, como atravessa o poema:

* Traduçáo do trabalho apresentado ao professor Graham Taylor, Exeter College, Unlvengldade de Oxford, durante o International Graduate Summer School, Julho de 1976 .

- Auxiliar de Ensino de Lingua e Literatura Inglesa da U.F.P. Licenciada em Letras Neo-Latinns (1959) e Letras Angla.Germanicas (1963). Mestra em Estudos Anglo-Americanos pela U.S.P. (1974), com a dissertaçäo Word, Imsge and Symbol in H.D.'s Early Nature Poctry. Cursos de Aperfeicoa. mento nas universldades de Montpellyer (1967) e Oxford (1975). Diplomas de Michigan, Cambridge, English Studieg e Nancy. Trabalhos publicados na Revista Letras: Henderton: from Chaos to Clarity (1971). The Opposing Forces in Albes's aThe Zoo Story (1972), Shelley and Debnssy (1973/4) Anślise do poems entre a Rala o Flor de Jorge de Lima (1975).

1 CONRAD, Joseph. Heart of Darkness, London, Penguin Books, 1975.

2 ELIOT, T.S. Collectod Poems 1909.1995. London, Faber \& Faber, 1951.

3 Homens ocos. vazios. (Nota da tradutora: a traduçăo literal de palavra:s dos textos de Eliot e Conrad visa apenas facllitar a compreensio do original ingles e năo e. em absoluto, uma traducho interpretativa dos textos originais).

4 CONRAD, 3. 100. «Seu. Kurtz - ele morto. 
We are the hollow men

We are the stuffed men

Leaning together

Headpiece filled with straw. Alas!

Our dried voices, when

We whisper together

Are quiet and meaningless

As wind in dry grass

Or rats' feet over broken glass

In our dry cellar

Shape without form, shade without colour,

Paralysed force, gesture without motion;

Those who have crossed

With direct eyes, to death's other Kingdom

Remember us - if at all - not as lost

Violent souls, but only

As the hollow men

The stuffed men. ... 5

Estes "hollow men" são os espectadores ou atores passivos na descida de Marlow às regiōes interiores do cordiforme continente africano, numa linha que nunca é reta, mas, como um parafuso, sonda mais e mais prefundamente o "centro da terra". E, em sua peregrinaçāo às nascentes do rio Congo, Marlow acha nāo a água cristalina da inocência e juventude - O Eldorado, como o nome da Companhia de Exploração Eldorado implica - mas as águas lodosas e negras da decadência e do mal. tanto físico como moral.

Como as caveiras postadas em volta da casa de Kurtz, os "hollow men", são, de certo modo, indicadores de caminho na viagem de Marlow à procura da verdade, da cogniçāo: eles estāo tāo "mortos" espiritualmente como as cabeças colocadas nos postes o estāo fisica-

5 ELIOT, eThe Hollow Mens (1, parte). in Collected Poems 1909.1935:

Nis somos c; homens ocos

Nis somos as homens empalhadox

Encostados funtos

Cabeca chein de palha. Ai:

Nossas vozas secas. quando

Sussurramos juntos

Sto silenclosas e inexpressiras

Como o vento em grama seca

On bés de rato sobre vildro quebrado

Em nosgo porbo sacn

Figura sem torma. sombra sen cor.

Forca paralisada. zesto sem morimento.

Aqueles que atraressaram

Com olhos fixos, ao outro Reino da morte

Lembram-se de nos - se o lazem - năo como

Almas violentas perdidas. mas apenas

Como os homens ocos,

Os homens empalhados... 
mente - e tão repugnantes também, em suas diferentes graduaçōes de "hollowness" ou de "greyness" 6 . Na realidade, é o fato de eles não screm nem negros nem brancos que mais os indicia aos olhos de Marlow e aos nossos próprios olhos. O "negrume" do coração de Kurtz 7 atinge a súbita percepção de Marlow como um mal menor do que os coraçōes "empalhados" 8 dos "hollow men". usando as palavras de Eliot. Kurtz atravessou - como Marlow está atravessando - "com olhos fixos ao outro Reino da morte" 9, a Africa, apenas para ter visto o seu "horror" - uma "alma violenta perdida" 10 como é a de Kurtz - enquanto aos "hollow men" nem lhes é permitido fazer isso, "sombras sem cor!" 11 que eles sāo.

E, como na peregrinação de Dante através do Inferno, nāo há cstrelas na descida de Marlow ao "inferno" africano, nem mesmo quando ele volta à civilização - contrastando com o poema de Eliot, em que há uma "estrela esvaecente" 12 e com o próprio Inferno da Divina Comédla, à cuja saída Virgília e Dante vêem as estrelas. Em sua jornada ao desconhecido, Marlow está rodeado de "peregrinos" com diferentes "profissōes" 13, cada qual com uma estória diferente para contar (quase como nos Canterbury Tales, com uma torçāo sardónica) - a estória de sua ineficiência e maldade.

Assim, se os quatro ouvintes da narrativa de Marlow (a bordo da "Nellie") podem ser considerados como não engajados, nāo comprometidos - excetuando talvez o narrador em primeira pessoa - é rcalmente nos europeus "brancos" que Marlow encontra ao chegar na Africa, que vamos concentrar nossa atenção.

De acordo com a natureza estéril 14 que Marlow acha na Estaçāo Externa - "uma caldeira rolando na grama, um truck de ferrovia tombado com a roda para o ar, partes de maquinaria deterioradas e uma pilha de trilhos enferrujados" 15 (que incidentalmente nos lembram um poema de Allen Ginsberg, "Sunflower Sutra" 16) - ele encontra, em primeiro lugar, seis negros avançando em fila. Estes passam por Marlow "sem um olhar, com aquela indiferença mortiça

6 Qualidade do que e oco, vazio: qualidade do que é cinzento.

7 Herz (coraç̄on em alemāo) e Korzenlovski (o verdadelro sobrenome d" Conrad) tém ambos uma evidente semelhança sonora com Kurtz.

8 ELIGT, 1.4: \&filled with straw.

9 Ibid.. 1.14: With direct eyes, to death's other Kingdoms.

10 Ibld., 1. 16-16: alost violent soulss.

11 Ibid.. 1. 11: shade without colour.

12 Ibid.. 1, 28: klnding gtars.

13 CONRAD, a. 37: epilgrimss, etrades*.

14 *Wasteland, no original, lembrando o noema de Ellot.

15 CONRAD, p. 22: \& A boiler wallowing in the grass, an undersized railway truck lying on its back with its wheel in the air, pleces of decaying machinery nind a ginck of rusty ralls .

16 sunflower Sutrax In Penzain Jodorn Poets, 5. London, 1970. p. 81.3. 
c total de selvagens infelizes" 17 , o que contrasta mais ainda com $n$ "arreganho branco e velhaco" 18 do guarda nativo uniformizado que os seguia.

Indo adiante, Marlow penetra "no círculo tenebroso de algum Inferno" 19 e tem uma visāo dantesca de negros agonizantes. "sombras negras de doença e inanição, deitados confusamente na escuridāo esverdeada" 20 . Horrorizado, ele se apressa em direção da Estaçāo, perto da qual inesperadamente encontra um homem branco vestido com elegância, o que mais uma vez destoa estranhamente com o que Marlow vira antes. Este homem é o contador-chefe dn Companhia, c seu comportamento insensivel em relação ao negro moribundo $\mathrm{cm}$ seu escritório é ainda mais realçado pela observação que faz a Marlow, para dizer a Kurtz que "tudo aqui vai muito bem 21. Apesar disso, Marlow "admira" a "grande compostura" 22 deste "fantoche", o primeiro dos "hollow men" brancos que ele encontra na Africa, e que "mantinha sua aparência" 23 apesar da grande desmoralização do pais.

Continuando caminho, no outro dia, à Estação Central, Marlow passa quinze dias numa rotina descrita como "acampar, cozinhar, dormir, levantar acampamento. marchar" 24, acompanhado às vezes pelo som de tambores distantes - "um som misterioso, apelante, insinuante e selvagem" 25. Chegando à Estação Central, Marlow vê "homens brancos com longos bastōes nas mãos emergindo languidamente por entre os prédios": 26 olhando-o e desaparecendo de novo. Esta é a primeira visão de Marlow dos "peregrinos", os negociantes da Companhia, levando seus "bastōes" e que formam mais uma vez uma espécie de cenário para a primeira entrevista de Marlow com o gerente.

Com seu "sorriso" furtivo, que ao mesmo tempo "não era um sorriso" 27, o gerente dá a Marlow uma sensação "inconfortável" 22. Como o próprio gerente dissera, "os homens que vêm até aqui nāo deveriam ter entranhas" 29, palavras que se tornam simbólicas pelo

17 CONRAD, p. 23: without a glance, with that complete deathlike indifference of unhappy savagegs.

18 Ibld.. ก. 23: en large, white, rascally grin.

19 Ibid.. D. 24: einto the gloomy circle of gome Infernos.

20 Ibld., p. 24: cblack shadows of disease and starvation, lying confusedly iI the greenish glooms.

21 Ibld., o. 27 : cererything is very entisfactors:.

22 Ibid., D. 27: egreat composures.

23 Ibid., p. 26: Kept up his appearances.

24 Ibld.. p. 28: camp, cook, sleep. strike camp. march.

25 Ibld., p. 28-9: a sound weird, appealing. euggestive, and wilds.

26 Ibld., p. 30: white men with long stares in their hands appeared languldly from amonget the buildinges.

7 Ibld., n. 31: - a smile - not a smile $\rightarrow$

28 Ibld., $n$. 31: cuneasinesss.

29 Ibid., p. 31: Men who come out here should hare no entrailss. 
sentido oculto - este homem aqui é "hollow" porque perdeu us entranhas espirituais, isto é, seu aspecto exterior civilizado esconde uma apática negligência em relação ao ambiente, permitindo que $\mathfrak{a}$ loucura da cobiça traga destruição à terra e ao negro. Ele é o epítome de um "hollow man", inspirando "nem amor nem medo, nem mesmo respeito" 30 .

Depois, Marlow passa alguns meses trabalhando no conserto do barco e, uma noite, encontra o jovem agente do gerente - na realidade, seu espiāo, que tenta "sondar" Marlow acerca de suas conexões européias. Este "oleiro" que não tem nada a construir parece i Marlow um "Mefistófeles de papel mascado" 31, em sua ambição mesquinha de se tornar vice-gerente. Sua única ocupação parece ser intrigar enquanto não se acharia "nada dentro dele, a não ser um pouco de sujeira" 32 .

Em scguida obtemos rápidos vislumbres do capataz um caldeireiro branco, desprezado pelos peregrinos porque ele realmente trabalhava: ele não é um "hollow man" e portanto é estimado por Marlow, para quem trabalhar significa "a chance de achar nossa própria realidade" 33. Inesperadamente, os "piratas" da Expedição de Eploraçāo Eldorado chegam, e sua conversa é descrita por Marlow como sendo "atrevida sem arrojo, gananciosa sem audácia, cruel sem coragem" 34, numa esplêndida sequência de oxímoros corroborando $a$ "hollowness" dos homens. Estes são dirigidos, em sua carência de "propósito moral", pelo tio do gerente, cujos olhos estāo cheios de "astúcia sonolenta" 35.

Por uma conversa que Marlow casualmente ouve entre o gerente e seu tio, na praia, ele percebe que Kurtz representa nāo apenas um perigo para as futuras promoçōes deles, mas permanece também uma incógnita para os mesmos, pela maneira que agiu, há um ano. Seus planos de abandonar Kurtz enfermo e sem provisōes, é apenas outra ilustração de seu código moral, de que "pođe-se fazer tudo neste país".36 Quando ambos voltam d estação, "eles pareciam arrastar penosamente colina acima suas sombras ridículas, de alturas diferentes". 37

Subir o rio, mais e mais para dentro do "coraçāo das trevas",38

30 CONRAD, p. 31: neither love nor fear, nor even respects.

31 Ibid., D. 37: $7 \mathrm{t}$ papler.maché Mephistopheless.

32 Ibld., p. 37: would find nothing inside but a little loose dirt, maybex.

39 Ibld., $p, 41$ : ethe chance of finding your own realitys.

34 Ibld., p. 43: creckless without hardihood, greedy without audacity, and cruel without courages.

35 Ibid., D. 44: «leeny cunnings.

36 Ibid., $p$. 46: eanything can be done in this country's.

37 Ibld., p. 48: sthey seemed to be tugging painfully uphill their two ridiculous shadows of unequal helght.

38 Ibid., p. 50: kheart of darknesss. 
era como "retornar aos primórdios do mundo". 39 Marlow sente, na "realidade esvaecente" 40 de sua viagem em direção a Kurtz, que ele está dirigindo um vagão como um "homem de olhos vendados" 41 numa estrada ruim. Os canibais que ajudaram a vadear o barco a vapor formam, por outro lado, um contraste salutar aos "hollow men" que Marlow encontrara, porque "eram homens com os quais se podia trabalhar" e eles "nāo se devoravam mutuamente" 42 na presença de Marlow, como os outros homens brancos faziam, metaforicamente.

Os brancos que Marlow encontra em diferentes estações rio acima parecem estar "cativos por uma magia", 43 enquanto o vislumbre que ele tem dos nativos nas margens, com seus gritos, batendo os pés e oscilando os corpos, nos transmitc que eles são livres - novamente num estranho contraste com a primeira cena que vimos, quando Marlow chega à Estação Externa. Aqui, os nativos podem mostrar sua verdadeira força, eles ainda sāo verdadeiros homens, eles ainda nāo se tornaram "hollow men", ainda nāo perderam sua vitalidade. nāo se tornaram as máscaras grotescas, as "sombras" ambulantes da Estação Externa, física e espiritualmente submetidos a seus contrapartes, os "hollow men" brancos.

0 foguista de quem Marlow cuida, no barco, parece ser uma ctapa intermediária entre a verdade primitiva e selvagem representada pelos canibais do "coração das trevas" e os selvagens explorados pelos brancos - ele é um "selvagem destribalizado" porque ainda tem cicatrizes ornamentais e seus dentes sāo "afilados", 44 enquanto cuida dos instrumentos de medição de vapor e água do barco.

A cincoenta milhas dentro do campo de açāo da Estação Inter. na, Marlow encontra uma cabana de juncos, dentro da qual acha uma mensagem e um livro sobre a arte de navegar. Tão interessado fica, naquela selva. que perde a noçāo de tempo, até que o gerente c os peregrinos a bordo, raivosos, o chamam de volta à realidade deles, de "hollow men". Então procedem, ou melhor, "se arrastam em frente", 45 por causa da rápida correnteza em scntido contrário (simbólica, para Marlow, da dificuldade em achar seu verdadeiro "eu", na direção de Kurtz).

Eles ancoram no meio do rio c, na neblina branca da manhā scguinte, Marlow e os peregrinos quase enlouquecem de medo ao ouvir um súbito grito na margem. Novamente o contraste é estabelecido entre o pavor na expressão dos "hollow men" brancos e a expressão

39 CONRAD, p. 51: etravelling in the night of linst agess.

10 Ibid., s. 49: efading reality.

41 Ibid.. n. 49: "a blindfolded mans.

42 Ibid., p. 49-50: they were men one could work with... they did not eat cach others.

43 Ibid., p. 50: captive by a spells.

44 Ibid., p. 52: efiled,.

45 Crawl ons no ortginal. 
"alerta mas tranquila" 46 nos rostos de seus companheiros negros. O "comedimento" destes é admirado por Marlow, não apenas em relação ao medo mas também em relaçāo à fome, pois "medo nenhum pode resistir à fome, paciência nenhuma pode saciá-la": 47 apesar de comerem a "insalubre" 48 carne estragada de hipopótamos, os negros têm melhor aspecto do que os peregrinos "insalubres", contrastados com a atitude estoica dos primeiros.

Apenas uma milha e meia abaixo da Estação Interna, o barco a vapor ć subitamente "atacado" por nativos, que atiram enxames de flechas nos homens a bordo. Uma lança mata o "piloto louco" de Marlow, outro nativo "destribalizado" cuja dupla identidade - ele não ć nem mais um nativo, nem ainda um homem civilizado - novamente o relaciona com os "hollow men" brancos. Sua morte é de certo modo simbólica das forças profundas que estāo em ação naqucle "coração das trevas" da mesma maneira que os brancos no centro da Africa parecem estar cativos, o Continente Negro também se vinga dos nativos que tentam tornar-se "civilizados", ao abandonarem seu status primitivo de selvagens "irracionais".

Na morte do piloto temos uma visāo burlesca de um "peregrino" de "pijamas cor-de-rosa, muito excitado e esbaforido" 49 na porta. Elc nāo fọi nem mesmo capaz de dirigir a embarcação, após a morte do piloto. Tanto os peregrinos como o gerente ficam então "escandalizados" quando Marlow atira o cadáver do piloto ao rio, enquanto outro peregrino fica "fora de si" de alegria que a matança dos nativos vingara o supostamente morto Kurtz.

Finalmente, o último "hollow men" que encontramos antes de chegar a Kurtz é um russo, à beira do rio, e que se assemelha a um "arlequim" com sua roupa remendada, sua "alegria", tão inconsciente do que "iria acontecer a ele quanto um nenê", o que se torna aparente em seu rosto "inexpressivo". 50 Esta estúpida inconsciência do que a vida ć coloca-o ao lado dos outros "hollow men", mesmo sc cle não ficou desmoralizado como os outros, por causa de sua insensatez. Foi até sugerido que se poderia ver neste russo uma projeção da juventude de Marlow, enquanto Kurtz seria uma projeçāo do outro "eu" de Marlow, do qual cle estava à procura, em sua viagem à Africa.

Concluindo. devemos lembrar-nos que esta descrição dos diferentes tipos de "hollowness" achados nas personagens secundárias de Heart of Darkness constitui apenas uma pequena fração da significação total da obra, mas uma fração crucial para a avaliação das duas personagens principais da obra, Mrlow e Kurtz. Além disso, es-

46 CONRAD, 1. 57: ealert... but... quiets.

47 Ibid., p. 60: erestraints; no fear can stand up to hunger, no patience can wees it outs.

48 Ibid., p. 61: sunwholesome».

49 Ibid., p. 66: sin pink pyjamas, very hot and agitedx.

50 Ibid., p. 75: cwhat would happen to him as a babys; efeaturelesss. 
RENAUX, S. O tema de The Hollow Men en Heart of Darkness de Joseph Conrad

te levantamento mostraria como houve um enriquecimento recíproco entre Heart of Darkness e The Hollow Men, pois o tema no romance é uma das chaves para a compreensão do poema, enquanto The Hollow Men aprofunda e amplia nossa visão das personagens do romance.

\section{BEFERENCLAS BIBLIOGRAFICAS}

CONRAD. Joseph. Feart of Darkness. London, Penguin Books, 1975. 111 p.

ELIOT, Thomus Etearns. Collected Poems 1909-19ss. London, Faber \& Faber. 1951. $191 \mathrm{D}$.

PENGUIN modern poets. Harmondsworth, 1971. 5.5 .

\section{Resumo}

O presente artigo visa mostrar a estreita relação existente entre as personagens secundárias de Heart of Darkness, romance de Joseph Conrad, e o tema de The Hollow Men, poema de T. S. Eliot. Conclui-se que, apesar de Eliot ter sido influenciado pela obra de Conrad, que lhe é anterior, por sua vez c poema também nos ajuda a interpretar as personagens de Conrad. num processo de mútuo enriquecimento.

\section{Summary}

The aim of this article is to show the deep relationship which exists between the secondary characters in Joseph Conrad's Heart of Darkness, a novel, and the theme of T. S. Eliot's poem The Hollow Men. As a conclusion, one could say that although Eliot has been influenced by Conrad's work, written many years before, the poem itself also helps us to interprete Conrad's characters, in a doubly enriching process. 